\title{
Detection of Diseases in Sugarcane Using Image Processing Techniques
}

\author{
K.Thilagavathi ${ }^{1 *}$, K.Kavitha ${ }^{2}$, R.Dhivya Praba ${ }^{3}$, S.V.Arockia Joseph Arina ${ }^{4}$ and R.C.Sahana ${ }^{5}$ \\ ${ }^{1}$ Asst.Professor, Department of ECE, Kumaraguru College of Technology, Coimbatore, India \\ ${ }^{2}$ Professor, Department of ECE, Kumaraguru College of Technology, Coimbatore, India \\ ${ }^{3}$ Asst.Professor, Department of ECE, Kumaraguru College of Technology, Coimbatore, India \\ ${ }^{4,5}$ UG Students, Department of ECE, Kumaraguru College of Technology, Coimbatore, India
}

\section{ABSTRACT}

India is one of the largest producers of sugarcane and ranks second in the world. The cropping season and duration of sugarcane depends on the varieties and sowing time. The time taken for its maturity is between 12 and 18 months. With high sensitivity to the environment, it easily gets affected by numerous diseases and pests. If the affected plant is not identified and taken adequate measures at the right time, it will affect the whole yield. The present study focuses on detecting various diseases in sugarcane leaves using the image processing techniques and developing a web application for the farmers to detect the major diseases of sugarcane as well. The system collects the images of the leaves and processes by means of Adaptive Histogram Equalization (AHE) superseded by segmentation using k means clustering algorithm. Using Gray Level Co-occurrence Matrix (GLCM) and Principal Component Analysis (PCA), statistical characteristics such as variance, skewness, standard deviation, mean, and covariance are extracted. Finally, the detection and classification are implemented using Support Vector Machine (SVM) that results the average accuracy value of 95\%. If any variety disease is identified, the required control measures are also suggested.

\section{KEY WORDS: SUGARCANE, FEATURE EXTRACTION, DISEASE, CLASSIFICATION, SUPPORT VECTOR MACHINE.}

\section{INTRODUCTION}

India stands first amidst the sugarcane growing countries worldwide in terms of area beforehand (3.93 m.ha) and second in production (167 m.t). Despite the increase in the substantial yield per hectare in our country, the productivity of sugarcane is still lower when compared to other countries. The long duration crop faces various abiotic problems like shortage of water, differences in temperature, floods, nutritional lag, and alkalinity.

\section{ARTICLE INFORMATION}

*Corresponding Author: thilagavathi.k.ece@kct.ac.in Received 27th Oct 2020 Accepted after revision 14th Dec 2020 Print ISSN: 0974-6455 Online ISSN: 2321-4007 CODEN: BBRCBA

Thomson Reuters ISI Web of Science Clarivate Analytics USA and Crossref Indexed Journal

\section{Clarivate
Analytics}

NAAS Journal Score 2020 (4.31) SJIF: 2020 (7.728)

A Society of Science and Nature Publication,

Bhopal India 2020. All rights reserved.

Online Contents Available at: http//www.bbrc.in/

Doi: http://dx.doi.org/10.21786/bbrc/13.11/24
Fungal diseases such as brown spot, wilt, rust, red rot, and smut caused by photo plasma and viral diseases like sugarcane streak mosaic, sugarcane mosaic virus, yellow leaf syndrome affect the yield greatly. Pests such as sugarcane borer, white wooly aphid are also not the least responsibility for the reduced yield of sugar productivity. Being a prominent cash crop of India, it tops the list by serving feed for live stocks, as fuel and its stubble and roots as organic manure. These diseases limit the sugarcane production and bring forth heavy losses. It is reported to have more than fifty diseases in sugarcane leaves. The most destructive agents are fungi, bacteria, viruses, and nematodes [Viswanathan and Rao, 2011]. The causes, symptoms,transmission, and control measures of these severe diseases are explained below. 
Eyespot: Helminthosporium sacchari causes the eyespot disease in sugarcane. It grows from 6 - 7 months and is more susceptible to the disease. There occurs lessions which resemble small and water soaked spots initially and protrudes deeper into the surrounding tissues. The use of Foliar's 0.3\% Mancozeb or 0.2\% copper oxychloride with 2 to 3 sprays over the duration of 10 to 15 days can minimise the disease. Spraying should be done based on the severity of the disease. [https://plantvillage.psu.edu/ topics/sugarcane/infos]. Leaf Scald: Leaf Scald is another disease caused by Xanthomonas Albileneans. This disease may be controlled effectively by several methods. The disease resistant breeds can be approached from nurseries and are cultivated. These cuttings can be developed using sets which have undergone a cold soak/long hot-water treatment. After treatment with hot- water at $50^{\circ} \mathrm{C}$ for 3 hours, the cuttings are allowed to soak in cold flowing water for 48 hours. [https://plantvillage.psu.edu/topics/ sugarcane/infos].

Yellow Leaf: The sugarcane yellow leaf is affected by the Sugarcane Yellow Leaf Virus (SCYLV).The yellowing extends from the leaf midrib across leaf blades during the monsoon season until a general yellowing of the leaves can be seen from a distance.[Devi Aruna,2016]. The most successful method for the control of sugarcane diseases is to boost varietal resistance breeds. The lack of knowledge in choosing the variety of genetic yellow leaf resistance breed makes the crop development difficult for this disease. [Viswanathan and Rao,2011].

Red Rot: A fungal disease caused by Colletotrichumfalcatum Wentis is called Red rot. The noticeable signs during severe crop infection are dull red to brown shades on the rind / nodal regions, pinkish porulation at the rind and leaf scars. The leaves can be treated for 15-20 minutes by dipping them in 0-1 percent carbendazim (Bavistin). This should be done before primary and general cane planting. Spraying should be performed immediately after the outbreak of the disease. [https://sugarcane. icar.gov.in/index.php/en/2014-04-28-11-31-50/majordiseases] Mosaic: The mosaic disease is caused by the Sugarcane Mosaic Virus (SCMV) / Sugarcane Streak Mosaic Virus (SCSMV). Roguing the infected plants to eliminate SCMV can been successful. Incorporating inoculum pressures, a control measure, are not expressive among the use of mosaic- free seed canes. Planting material thermo-therapy may result in SCMV-free among some plants. The creation and use of resistant clones dominated the mosaic in sugarcane for a long time. [Devi Aruna, 2016].

Ringspot: It is caused by the fungus Leptosphaeriasacchari. Tiny, elongated, oval-shaped spots turning from dark olive green to reddish-brown with thin yellow halos, are the initial signs of a ring-spot. Spots are often visible on the leaf sheaths and stems. Mostly the older leaf blades are become the most affected part of the plant. Soil amendments and calcium silicate slag produces a substantial positive effect on yield reducing the intensity of ring spots.

\section{MATERIAL AND METHODS}

The authors Al Hiary et al,2011, suggested an algorithm for the automatic detection and classification of leaf diseases in plants that are experimentally tested. The algorithm has four main phases. First, the algorithm identifies green colored pixels in the leaf. The identified green pixels have masked using the threshold computed by Otsu's method. Then the pixels of the infected clusters were identified and removed. Then k-means clustering, and Neural Networks (NNs) were implemented for clustering and classification of plant diseases. Dheeb et al.,2011, suggested a framework to identify the leaf/stem diseases. The algorithm was tested with the images of the plants distressed by six distinct forms of diseases. Various soft computing / image segmentation methods proposed by Vijai Singh and Misra AK (2017) for the classification of plant diseases are analysed in this paper. The authors also propose an algorithm that automatically classifies and detects plant diseases by means of image segmentation and classification approaches. Further, the performance characteristics of the suggested algorithm has been tested on the images of various infected plants. From the survey it has been understood that by combining different algorithms could increase the cognition rate.

The input leaf image is pre-processed primarily using AHE in the proposed work and pre-ceded by the segmentation using k-means clustering algorithm, which utilises rehearsal refinement to produce the final result. The statistical features are extracted using GLCM and PCA. Finally the detection and classification are implemented through SVM and it compares the extracted image to the reference image. The displayed results infer whether the leaf is affected. If any leaf is affected with any disease, the disease type is identified. The various steps involved in the proposed method are given in the flow diagram, in the figure 1 . The images are processed beforehand the classification. All type of data given is conditioned using enhancing, displaying, and extracting information. The methodology for detection of diseases on the sugarcane leaf is done using MATLAB software [Sandesh 2017].

The input of the developed application is the image of the leaf and is processed using adaptive histogram equalization. Segmentation is carried out with $\mathrm{k}$ means clustering algo-rithm that produces tighter clusters, particularly when they are globular, than any other clus-ters. Then extraction is performed using Grey level co-occurrence matrix and Principal Component Analysis and finally the detection and classification is implemented using sup-port vector machine. The diseased and healthy leaves of sugarcane are placed in the database for android applications. So, the extracted image is compared with that reference image.

The results show whether the leaf is affected or not. If any affected attempts with disease are noted, the remedies are also displayed. [Sanjay et al 2013] The 
implementation specifics of the work proposed are listed in this section.

Figure 1: Proposed method

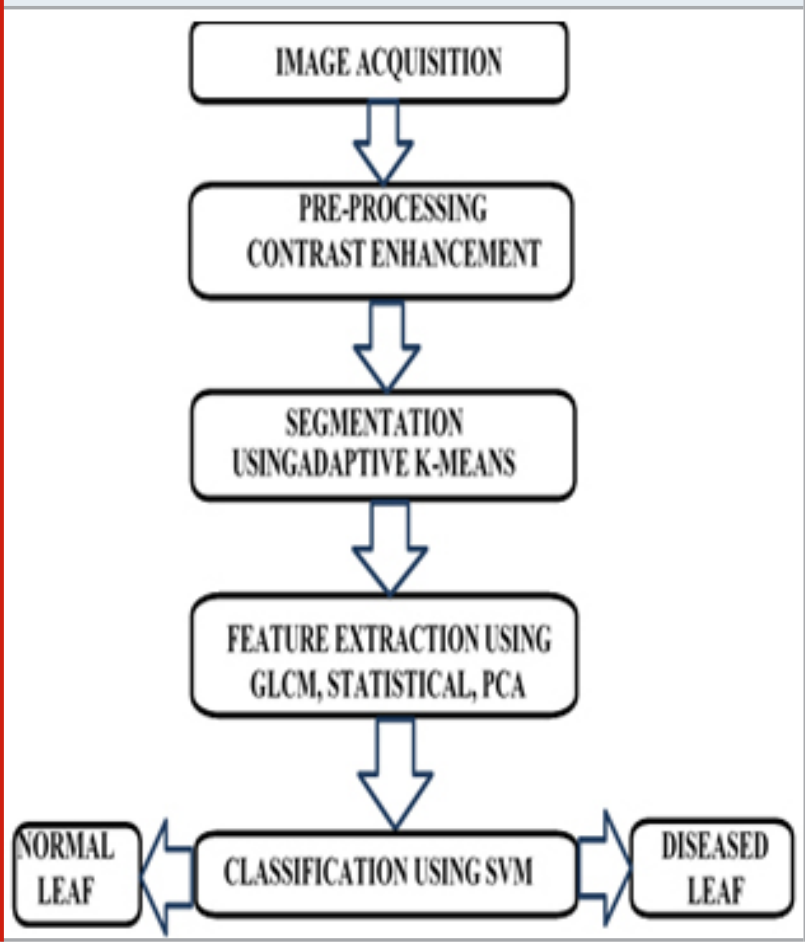

Figure 2: Bounding planes, Support vectors and Maximum Margin in SVM

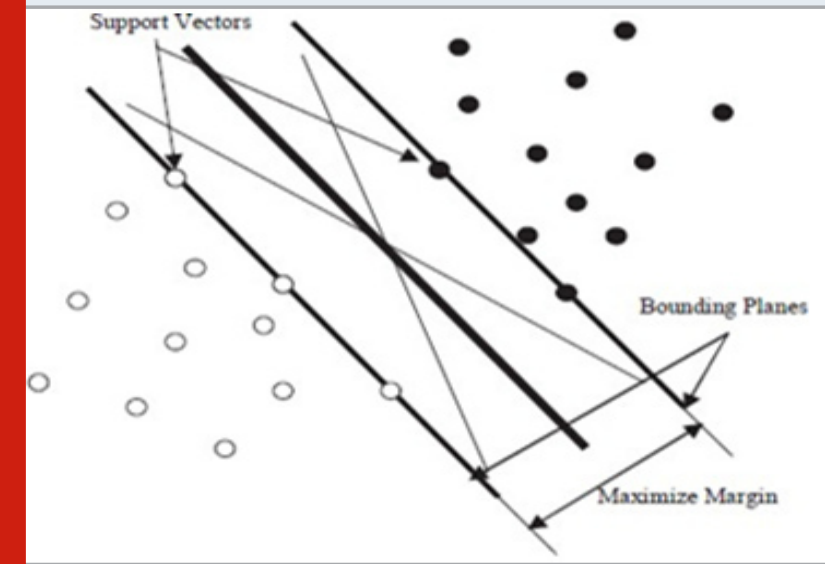

(i) Adaptive Histogram Equalization: Adaptive histogram equalization (AHE) is a computer-ized image preprocessing technique used to get a high improvement in contrasting the images. This method performs several histograms, wherein each histogram represents the distinct portion of the image, and then redistribution is done based on the image tone. Therefore, it helps in the enhancement of edges and in the improvement of local contrast of an image.

(ii) Adaptive k-Means Clustering: k-means clustering is an algorithm that comes under the unsupervised learning group. The primary intent of this $\mathrm{k}$-means 111 clustering algorithm is to construct $\mathrm{k}$ number of groups based on similar features. As a result, centroid is chosen for each cluster in order to create a new label data and this is followed by training the label data. This algorithm helps in identifying and analysing the groups that have evolved organically instead of segmenting groups without looking at the data. The weights of the centroid help to understand what sort of group each cluster specifies [Jagan et al.,2016]. This algorithm uses rehearsal refinement to generate the result. The inputs of the algorithm are the numbers of data set and the clusters $\mathrm{k}$. The algorithms starts with the estimation of the k centroids and then repeats between three steps: Data Assignment, Centroid Update and Choosing k.

(iii) Feature Extraction: Feature extraction is a process in which the informative features extracted and it is similar to dimensionality reduction. Whenever there is redundancy in the input data or if the input data is too large, feature extraction is performed to reduce the data. In character recognition system, the feature extraction is usually done after the pre-processing phase [Reddy etal.,2017]. Feature selection is nothing but determining the subsets of the initial features. It is the critical stage in the entire process as the classifier cannot recognize from the poorly selected features. It is helpful in achieving better performance as well.

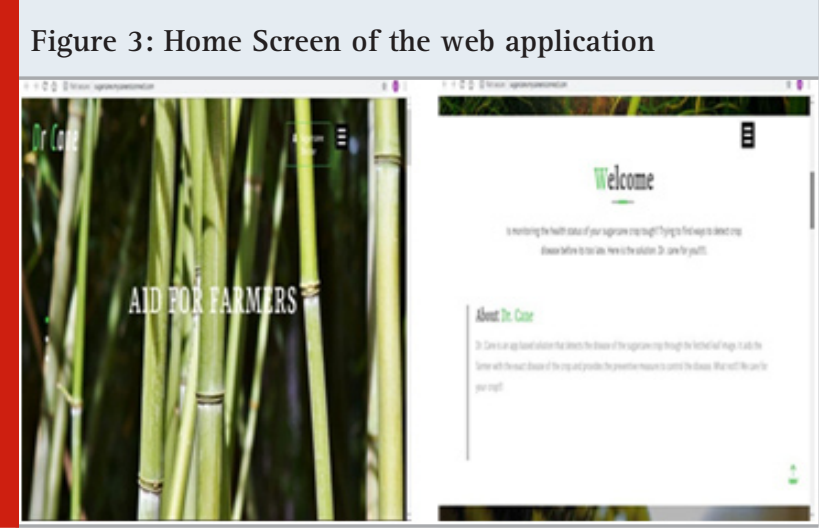

Figure 4: Leaf disease details in Web Application

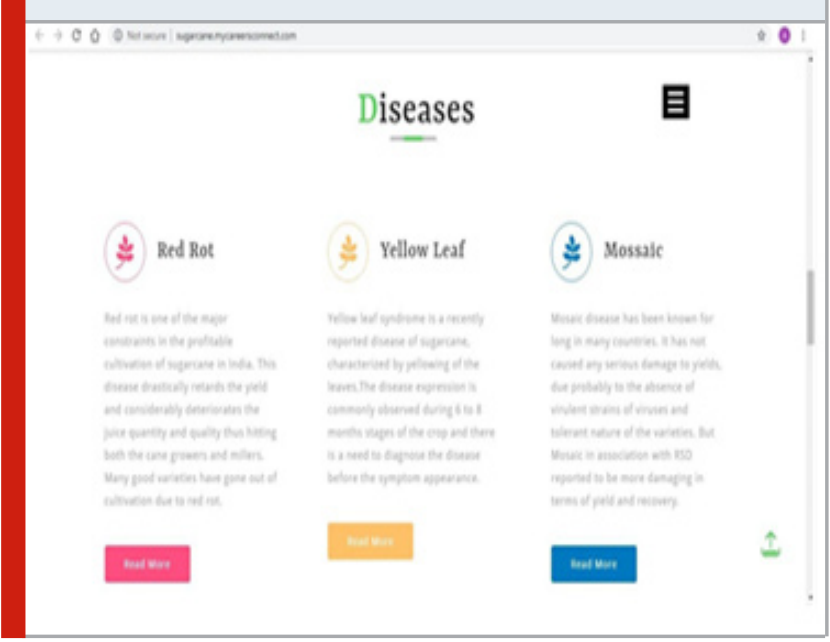


(iv)Gray-Level Co Occurrence Matrix: It is one of the statistical techniques for texture analy-sis. It deals with the spatial relationship of pixels and is often referred to as the spatial dependency matrix of the gray-level. In estimating the joint probability distribution, the average occupancy level of the matrix should be greater. This is accomplished by limiting the number of levels of amplitude quantization, which could decrease the precision of the texture of low-amplitude. Each element $(\mathrm{i}, \mathrm{j})$ in the resulting GLCM represents the sum of the number of times the pixel with value $i$ that occurred in relation to the pixel of $\mathrm{j}$ [Reddy et al.,2017], where $\mathrm{i}$ represents the intensity value and $\mathrm{j}$ represents the pixel value. The required step to calculate a GLCM for the complete dynamic picture is prohibitory and gray comatrix scales the input image. Gray comatrix performs scaling operation by default to reduce the intensity values of the gray scale image from 256 to 8 . The number of grey levels shows the scale of the GLCM [Devi Aruna,2016].

(v) Principal Component Analysis: PCA is a kind of statistical method which creates new un-correlated variables known as principal parts using orthogonal transformation. The ensuing vectors are the unrelated set of orthogonal basis. PCA is susceptible to the relative size of the initial variables. PCA is performed by eigenvalue decomposition of an information variance matrix or singular worth decomposition of an information matrix. Every attribute is standardized by mean centering such that its empirical mean value is zero. The nonstandardized attributes are eigen vectors. They are the cosines of orthogonal rotation of variables into principal elements or back [B.Chitradevi, P.Srimathi,2014].

(vi)Classification: Classification deals with the wide range of decision-theoretic approaches for image identification. The image in question has one or many features and these classification algorithms helps in classifying the image to one of the distinct classes based on the features. The classes are specified in prior by the analyst [Shweta and Shandilya,2018]. The different types of well-known classifiers are Support vector machines, Quadratic classifi-ers, Linear classifiers, Learning vector quantization, Kernel estimation, Neural networks, and Decision trees.

(vii)Support Vector Machine: It is one of the wellsuited algorithm for image classification. To classify the images remotely, Kernel based image classification is mostly used. SVM with multiple kernels is used for the classification of images with kernel optimization. Feature extraction is an important process that must be carried out before classification, because the images are categorized on the basis of the extracted features. SVM Kernel method provides a good solution for regression and classificationbased problems. This is a supervised machine learning algorithm and the two different classes are separated by a hyperplane. If the classes are separated with the larger margin, then it has minimal error. The minimum error is used to predict the correct class of the data without any error in the classification process [Chitradevi, P.Srimathi,2014].
There are two parallel planes called "Boundary planes" and the distance between these two planes is known as 'margin'. The points that lie on the boundary planes are called 'support vectors' [Shweta and Shandilya,2018]. It is one of the best and popular method used for image classification. The support vectors (Figure 2) are the data in the data set which defines the maximum margin. Web Application Development: The Web based application provides the control measures of identified sugarcane diseases. This application helps to identify six diseases of sugarcane and provides their symptoms and precautions. The user can access the web application using the link http://sugarcane.mycareersconnect.com/. In the application, images of infected leafs are compared using pixel by pixel comparison method. The uploaded image is matched with the images existing in the database. The hexacode of the RGB colors is calculated for each pixel of both the images and stored in two different matrices. Then these matrices are compared with each other and when the two images have more than 80\% similar pixels, it would give the desired result.

Figure 5: Results for RINGSPOT: a) Input RGB image b) Resized image c) Grayscale image d) Contrast enhanced image e) Segmented image f) Classified result
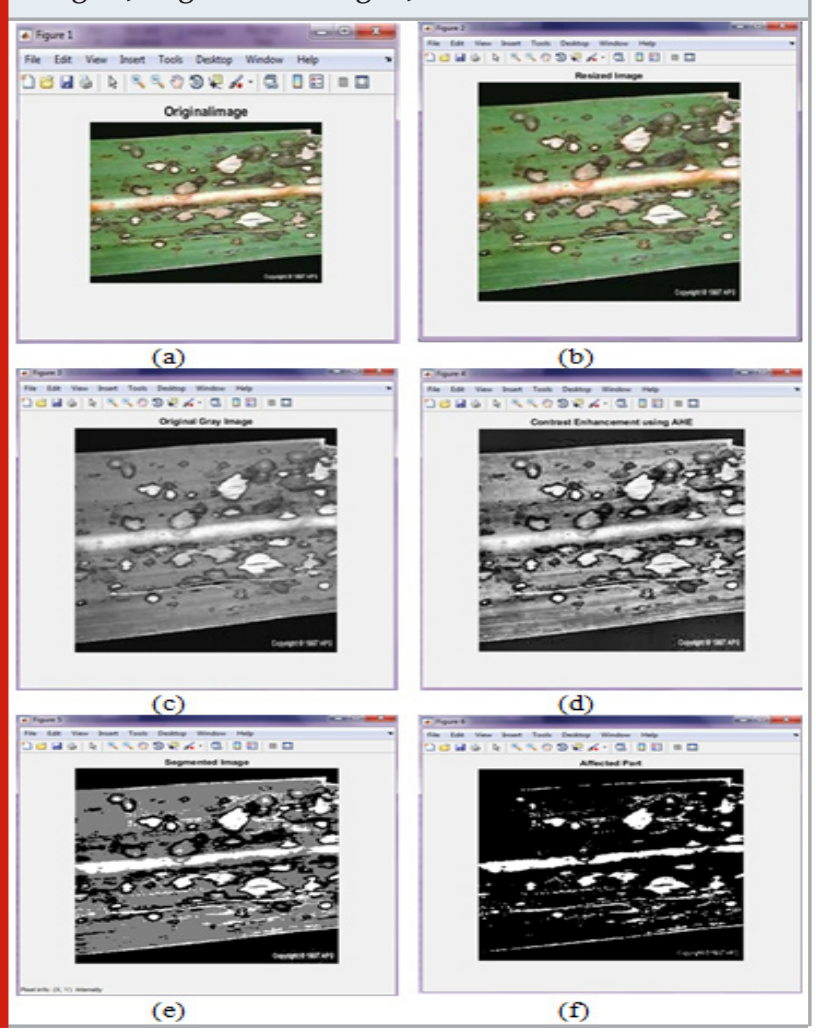

The web application for our system is targeted to be used by farmers or the people who are involved with the production process of Sugarcane. It will benefit them in a way that gives them solution within a short period for the experts. Since it is a web-based application, made accessible to all the farmers regardless of their physic allocation. The home screen of web application and the leaf disease details are shown in Figures 3 and 4 respectively. 
Figure 6: Results for Mossaic: a) Input RGB image b) Resized image c) Greyscale image d) Contrast enhanced image e) Segmented image f) Classified result
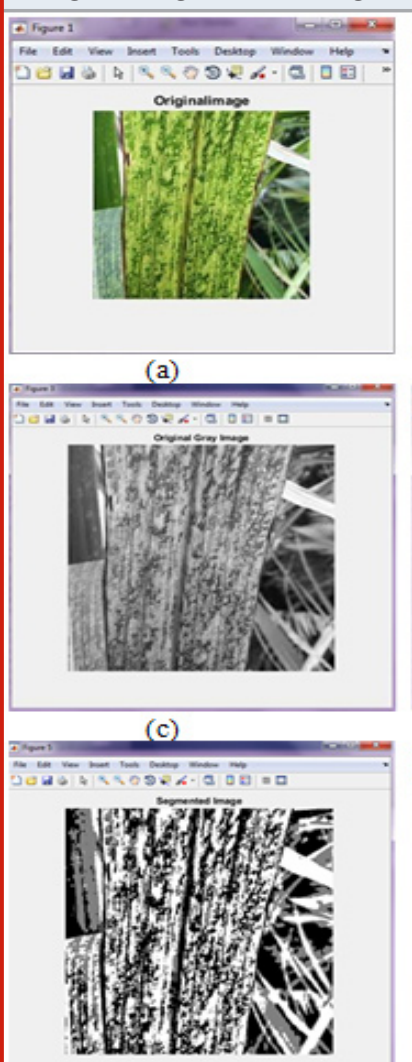

(e)
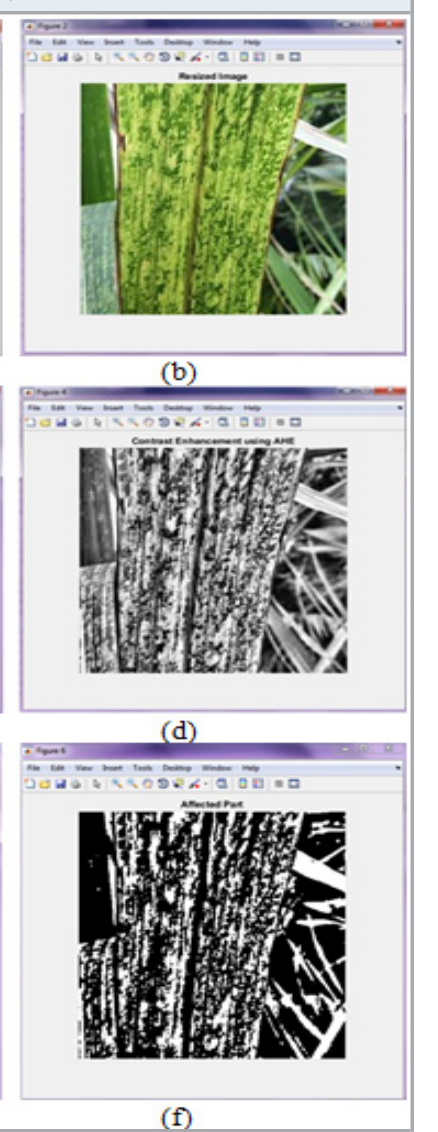

Figure 8: Results for EYESPOT: a) Input RGB image b) Resized image c) Greyscale image d) Contrast enhanced image e) Seg-mented image f) Classified result
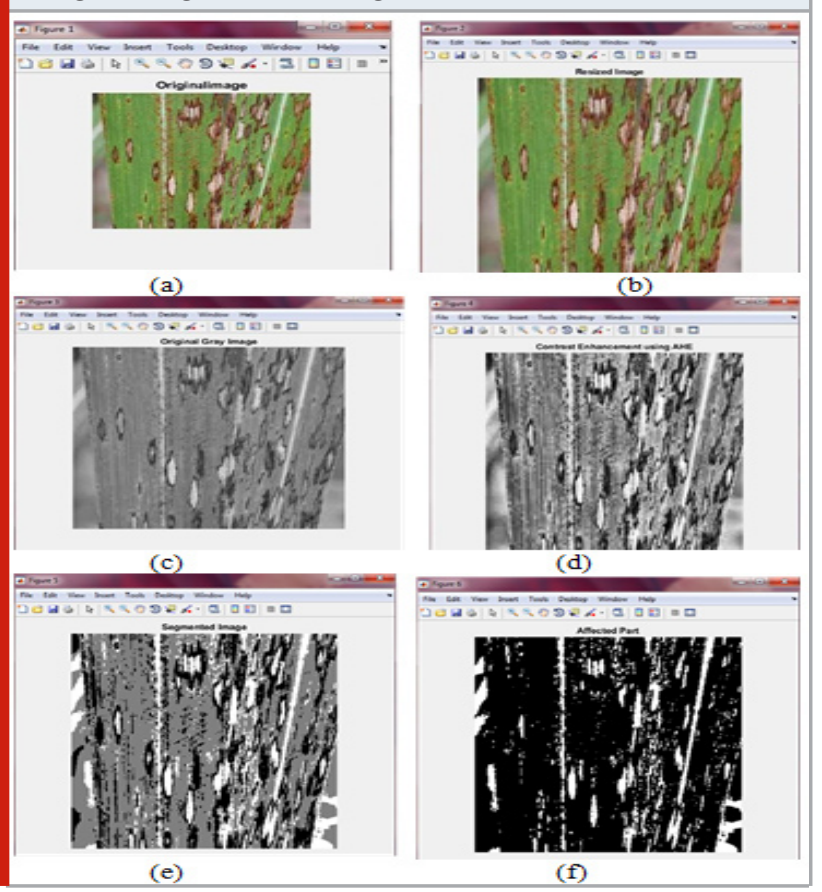

Figure 7: Results for Red Rot:a) Input RGB image b) Resized image c) Greyscale image d) Contrast Enhanced image e) Segmented image f) Classified result
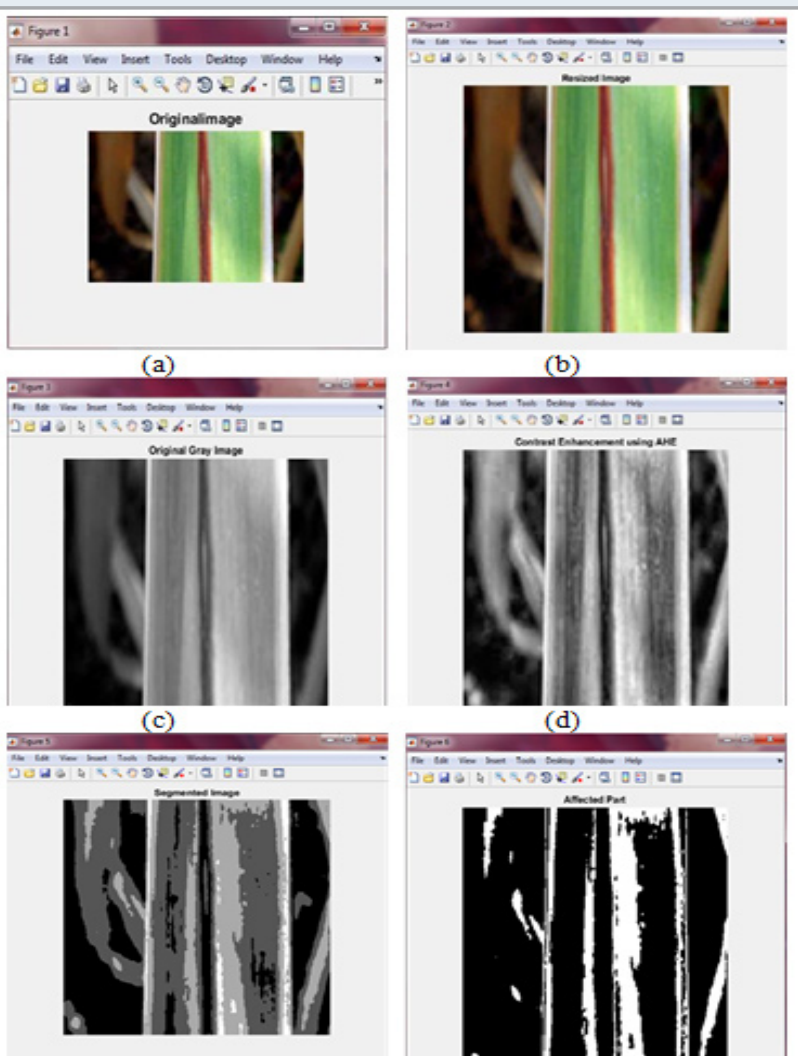

(e)

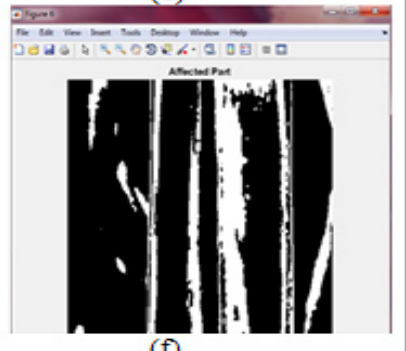

Figure. 9: Results for yellow leaf a) Input RGB image b) Resized image c) Greyscale image d) Contrast enhanced image e) Segmented image f) Classified result.

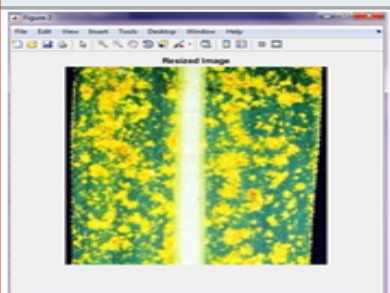

(a)

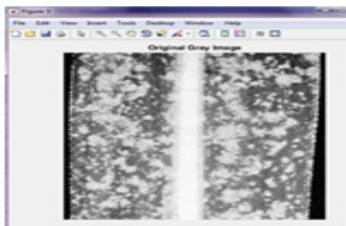

(c)

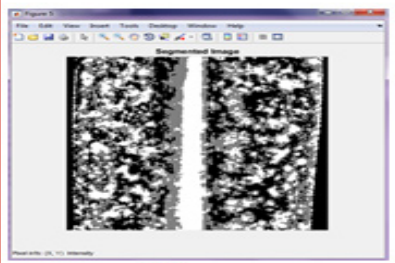

(e)

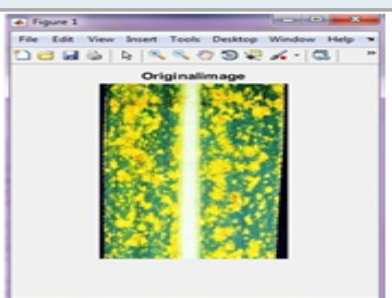

(b)

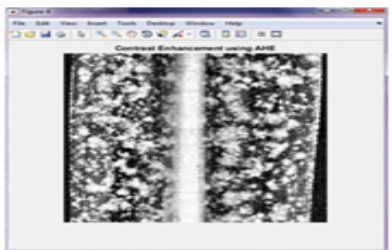

(d)

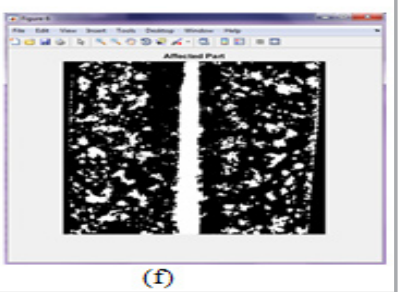




\section{RESULTS AND DISCUSSION}

The diseased leaf of sugarcane is acquired and through image pre-processing technique where the unwanted image data are suppressed. The image is enhanced through AHE. Then, the process of segmentation is done through Adaptive k-Means Clustering. The desired features are extracted by using GLCM and PCA. Finally, the classification of diseases is done through SVM. The above described process is executed in MATLAB software and the obtained results for six sugarcane diseases are shown in figures from 5 to 10.

Figure 10: Results for leafscald: a) Input RGB image b) Resized image c) Greyscale image d) Contrast enhanced image e) Segmented image f) Classified result

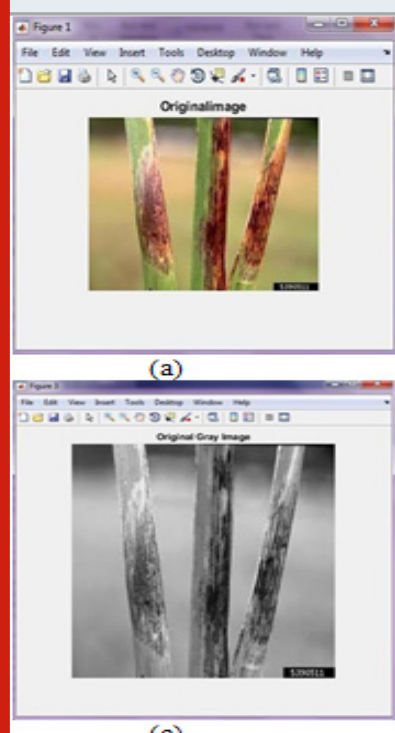

(c)

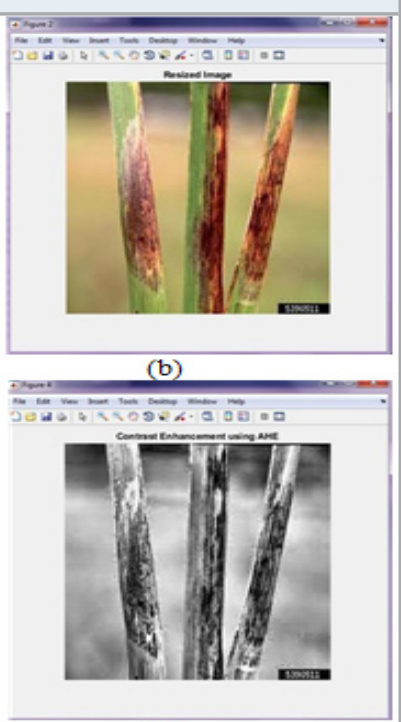

(d)
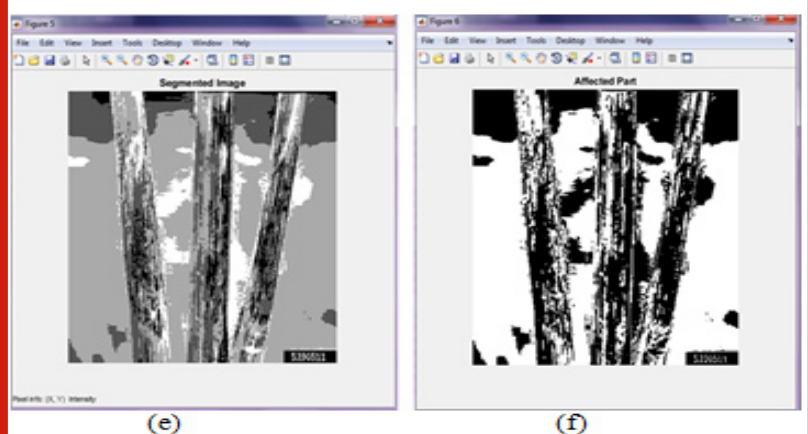

\section{CONCLUSION}

In present situation, it is difficult for farmers to keep an eye on each plant in the growing area and detect the manifestation of any infection. To serve the function of a watchdog by detecting the disease and determining the form of the disease in the leaf, image processing techniques have been developed. The combination of various feature extractions (GLCM and PCA) with SVM classifier has been implemented to test six signifi-cant diseases which largely affect the sugarcane yield. The proposed system achieved the ac-curacy value of 95\%.
A detailed review of the causes and symptoms of all sugarcane diseases is highlighted in this article. The web application developed for our system is targeted for the farmers to apply it. It will benefit them with desirable solutions within a short span of time. As a future work, various classification methods can be tried to increase the efficien-cy of the system in which and the system can be improved by a broader data set for the identification of all forms of sugarcane diseases. For the web application part, the information can be made available in the regional language.

\section{ACKNOWLEDGMENTS}

This work was funded by Tamil Nadu State Council for Science and Technology under Stu-dent Project Scheme. Authors would like to thank ICAR-Sugarcane Breeding Institute, Coim-batore for providing the database of sugarcane leaf disease to carry out the work.

Conflicts of interest: The authors declare no conflict of interest.

\section{REFERENCES}

Al-Hiary H, Bani-Ahmad S, Reyalat M, Braik M and ALRahamneh Z 2011, "Fast and accu-rate detection and classification of plant diseases", International Journal for computer applica-tions, Vol 17 No 1. Pages 31-38. Baddeli sravya reddy, Deepa R, Shalini S, Bhagyadivya P 2017, “A novel machine learning based approach for detection and classification of sugarcane plant disease by using DWT", International Research Journal of Engineering and Technology, Vol 04 No 12.Pages 843846.

Chitradevi,B, P.Srimathi 2014, "An overview on image processing techniques”. Interna-tional Journal of Innovative Research in Computer and Communication Engineering, Vol.2,No 11. Pages 6466-6472.

Devi Aruna.D 2016,"A Survey on Different Disease and Image Processing Techniques in Sugarcane Crops”,IJSRD International Journal for scientific Research \& Development, Vol.3 No 11.Pages 323-325. Dheeb AlBashish, Malik Braik and Sulieman Bani-Ahmad 2011, “A framework for detection and classification of plant leaf and stem diseases”, 2010 International Conference on Signal and Image Processing. 10.1109/ ICSIP.2010.5697452.Pages 113-118.

https://plantvillage.psu.edu/topics/sugarcane/infos

https://sugarcane.icar.gov.in/index.php/en/2014-04-2811-31-50/major-diseases

Jagan Bihari Padhy, Devarsiti Dillip Kumar, Ladi Manish and Lavanya Choudhry 2016,"Leaf Disease Detection Using k Means Clustering And Fuzzy Logic Classifier”, In-ternational Journal of Engineering Studies and Technical Approach, Vol 02, No. 5.Pages 1-7.

Sandesh Raut, Amit Fulsunge 2017, "Plant Disease 
Detection in Image Processing Using MATLAB”. Vol 6 No 6. Pages 10373-10381.

Sanjay B. Dhaygude, Nitin P.Kumbhar 2013,“Agricultural plant Leaf Disease Detection Using Image Processing International Journal of Advanced Research in Electrical, Elec-tronics and Instrumentation Engineering Vol. 2 No 1.Pages.599-602.

Shweta R. Astonkar, Shandilya VK 2018, "Detection and Analysis of Plant Diseases Using Image Processing
Technique International Research Journal of Engineering and Technology Vol.05 No.04.Pages 3190-3193.

Vijaisingh, Misra AK 2017, "Detection of plant leaf diseases using image segmenta-tion and soft computing techniques”, Information Processing in Agriculture, Vol 4 No 1 Pages 41-49.

Viswanathan R, Rao GP 2011," Disease Scenario and Management of Major Sugarcane Diseases in India”, Sugar Tech, Vol 13 No 4, Pages 336-353. 